\title{
Changes in the Epidemiology of Cutaneous Leishmaniasis in Northeastern Iran
}

\author{
Kuzeydoğu İran'da Kutanöz Leishmaniasisin Epidemiyolojisindeki \\ Değişimler
}

\author{
(1) Bibi Razieh Hosseini Farash ${ }^{1,2,3}$, (1) Seyed Ali Akbar Shamsian ${ }^{1}$, (1) Masoud Mohajery ${ }^{1}$, \\ (1) Abdolmajid Fata ${ }^{1,3}$, (1) Fatemeh Sadabadi ${ }^{1}$, (1) Fariba Berenji ${ }^{1}$, (1) Pietro Mastroeni ${ }^{4}$, (1) Elham Poustchi ${ }^{1}$, \\ (1) Elham Moghaddas ${ }^{1}$, (1) Ghodratollah Salehi Sangani ${ }^{1}$, (1) Gholamreza Farnoosh ${ }^{5}$ \\ ${ }^{1}$ Mashhad University of Medical Sciences Faculty of Medicine, Department of Parasitology and Mycology, \\ Mashhad, Iran \\ ${ }^{2}$ Tehran University of Medical Sciences Faculty of Public Health, Department of Parasitology and Mycology, \\ Tehran, Iran \\ ${ }^{3}$ Cutaneous Leishmania Research Center, Faculty of Medicine, Mashhad, Iran \\ ${ }^{4}$ Cambridge University, Department of Veterinary Medicine, Cambridge, United Kingdom \\ ${ }^{5}$ Applied Biotechnology Research Center, Baqiyatallah Medical Sciences University, Tehran, Iran
}
Cite this article as: Farash BRH, Shamsian SAA, Mohajery M, Fata A, Sadabadi F, Berenji F, Mastroeni P, Poustchi E, Moghaddas E, Sangani GS. Changes in the Epidemiology of Cutaneous Leishmaniasis in Northeastern Iran. Turkiye Parazitol Derg 2020;44(1):52-7.

\begin{abstract}
The province of Khorasan-Razavi in the North East of Iran is an endemic area for anthroponotic cutaneous leishmaniasis (ACL caused mainly by Leishmania tropica) and zoonotic cutaneous leishmaniasis (ZCL caused mainly by Leishmania major). Based on clinical signs, some cities were considered as ACL foci while others were considered to be endemic for ZCL.

This paper reviews studies performed on patients diagnosed with cutaneous leishmaniasis (CL) via the use of direct slide examination, ELISA, electrophoresis isoenzyme, RAPD PCR and PCR in Mashhad; the study also includes cases of CL in other cities of the Khorasan-Razavi province where only PCR used as a diagnostic tool. The data show that both Leishmania tropica and Leishmania major caused CL in most of the cities investigated. Our review shows that Leishmania major was found in areas where ACL is prevalent and Leishmania tropica was observed in areas with high incidence of ZCL. This distribution represents a major change in the epidemiological pattern of Leishmania in the Khorasan-Razavi province.

Keywords: Cutaneous leishmaniasis, Leishmania major, Leishmania tropica, molecular and immunological techniques, KhorasanRazavi province.
\end{abstract}

\section{ÖZ}

Khorozan-Razavi eyaleti, Kuzey Doğu İran'da yer alan, anthroponotik kutanöz leishmaniasis (AKL'nin sebep olduğu Leishmania tropica) ve zoonotik kutanöz leishmaniasis (ZKL'ye sebep olan Leishmania major) için endemik bir bölge niteliğindedir. Bu çalışmada klinik önem bakımından bazı şehirler AKL olarak nitelendirilmesine karşılık bazı şehirler ZKL olarak tanımlanmıştır.

$\mathrm{Bu}$ araştırma, kutanöz leishmaniasis (KL) olarak teşhis edilmiş hastalardan elde edilen örneklerin direkt mikroskobik bakıyla teşhisleri ile ELISA, elektroforez, izoenzim, RAPD PCR ve PCR yardımı ile Meşhed'te gerçekleştirilmiştir. Bu araştırma aynı zamanda Khorozan-Razavi eyaletinde sadece PCR kullanılarak yapılan KL örneklerini de içerir. Yapılmış olan bu çalışmanın sonuçları araştırma yapılan şehirlerin çoğunda Leishmania tropica ve Leishmania major'un KL enfeksiyonlarına sebep olduğunu göstermiştir. Bizim çalışmalarımızda AKL olgularının yaygın olarak görüldüğü bölgelerde Leishmania major'a rastlanırken, ZKL olgularınun yüksek oranlarda görüldüğü yerlerde de Leishmania tropica saptanmıştır. Bu dağılım Khorosan-Razavi eyaletindeki Leishmania'nın sebep olduğu olduğu hastalıkların dağılımını göstermektedir.

Anahtar Kelimeler: Kutanöz leishmaniasis, Leishmania major, Leishmania tropica, moleküler ve immünolojik teknikler, Khorasan-Razavi bölgesi 


\section{INTRODUCTION}

Leishmaniasis is a vector-borne disease caused by protozoa belonging to the Leishmania genus. Cutaneous leishmaniasis (CL) is the most common form of leishmaniasis in the Middle East. CL is transmitted by the bite of sand flies (a subfamily of Phlebotomine) (1). Humans and dogs are the main reservoirs of Leishmania tropica causing anthroponotic cutaneous leishmaniasis (ACL) with chronic, dry form, delayed ulceration and plentiful amastigotes. Wild rodents have an important role as reservoirs of Leishmania major causing zoonotic cutaneous leishmaniasis (ZCL) with acute, moist form, early ulceration and few amastigotes (2).

According to the World Health Organization (WHO) approximately 0.6-1 million new CL cases are estimated to occur worldwide annually; two-thirds of cases are in Afghanistan, Algeria, Brazil, Colombia, Iran and the Syrian Arab Republic (3).

Over the last decades a significant increase in the number of cases of leishmaniasis has been reported worldwide (4). This rise may be due to behavioral and environmental changes such as new settlements, deforestation, large migrations from rural to urban areas, fast and unplanned urbanization, building of dams and new irrigation projects that increase exposure of humans to sand fly vectors (5).

Prevention and control programs are directly dependent on targeting the right species of the parasite (6). However, the species of Leishmania that cause different forms of CL are morphologically similar, making differentiation between species by microscopy alone impossible. For this reason, alternative methods such as isoenzyme analysis and immunological approaches such as fluorescent dye-conjugated monoclonal antibodies_have been recently used for identifying Leishmania spp. (4). Furthermore, molecular methods based on PCR have also been used routinely by many laboratories to detect Leishmania in carrier hosts and to map parasite reservoirs $(7,8)$.

Several studies have been performed in the Khorasan-Razavi province to diagnose leishmaniasis from observation of clinical symptoms (9). However, information on the incidence of leishmaniasis based on new immunological or molecular methods is poor in this area. To improve diagnosis and eventually approaches to treatment, the University of Medical Sciences in Mashhad performed immunological and molecular studies to identify those Leishmania species that cause CL and to design plans for targeted epidemiological intervention in endemic cities of the Khorasan-Razavi province.

\section{METHODS}

This paper reviews clinical and epidemiological studies on leishmaniasis performed in the province of Khorasan-Razavi. The paper briefly reviews current global and Iranian epidemiological data on CL. The review compares previous data on CL in different cities of Khorasan-Razavi province with current epidemiological data. The paper is based on PubMed and Google Scholar literature searches from 1979 to 2018 using the following keywords: "CL", "prevalence OR epidemiology", "causative agents of CL OR molecular detection of Leishmania spp.". These key words were then, combined with "Iran" and "Razavi Khorasan OR Khorasan-Razavi province". Both papers in English and Persian were considered. We also considered data from graduate theses on epidemiology of CL and on molecular detection of Leishmania species in Khorasan-Razavi.

\section{RESULTS}

\section{Epidemiology of Cutaneous Leishmaniasis in Iran}

$\mathrm{CL}$ is one of the 10 most important parasitic diseases in tropical regions of the world, being present in all continents except for Australia (10). Investigations on various aspects of this disease have been prompted and supported by WHO and global burden of disease (GBD). According to GBD, the prevalence of CL has risen from 2.1 million in 2002 to nearly 4 million cases in 2015 (11-13). The number of individuals with latent $C L$ is estimated at about 12-20 million (10).

Disability-adjusted life years (DALY) due to CL is estimated at about 2 million years. Considering that only patients who are positive for Leishmania spp. are included in the DALY formula, and the psychosocial impact of scars due to CL (approximately 40 million cases) has not been taken into account, the real DALY is likely to be higher than the current estimated figure (13).

$\mathrm{CL}$ is the second most prevalent arthropod-transmitted disease in Iran (14). Despite the attempts of Iranian health officers to prevent and control leishmaniasis, the disease is still spreading and new foci of $\mathrm{CL}$ are reported every year. For example, 17 previously infection-free provinces of Iran are now endemic for leishmaniasis (15).

According to the data published by the Iranian Ministry of Health in 2011, about 20000 new CL cases are reported in Iran annually, while the actual number of patients with $C L$ is estimated to be four to five-fold higher. Patients with either moist or dry lesions are observed in both rural and urban areas in Iran (16). The rural form or ZCL with moist lesions is observed in 15 provinces of Iran including Isfahan, Sarakhs, Lotfabad, Khuzestan, Kashmar, Kashan, Dehloran and Damghan, whereas the urban form or ACL with dry lesions has been reported in Tehran, Shiraz, Mashhad, Neishabur, Kerman, Bam, Rafsanjan and Khomeyn Shahr $(16,17)$. Epidemiological studies in Iran indicate more than 90\% of CL cases occur in 88 cities and transmission occurs in 17 provinces in Iran with a prevalence rate ranging from $1.8 \%$ to $37.9 \%$ (18). Isfahan, Fars, Bushehr, Ilam, Khuzestan, Yazd, Semnan, Kerman, and Khorasan were high incidence areas between 1983-2013. A lower burden of infection was observed in Gilan, Kurdistan, Azerbaijan-West, Ardabil, Tehran, Qazvin, Hamedan, AzerbaijanEast, Kermanshah, Kohgiloyeh-Boyer-Ahmad, Lorestan, Markazi, and Chaharmahal- Bakhtiari. The last data about number of CL patients in different province of Iran during 2011-2013 has been shown in Table $1(16,19)$.

The incidence rate of $\mathrm{CL}$ follows a cyclical pattern of rise and fall between 20 to 40 cases per 100,000 people and a periodic trend lasting 5-6 years, which shows the limited effect of control measures that are transiently implemented in response to episodes of increased incidence of the disease (20).

Therefore, improved and permanent measures for epidemiological control of CL in Iran must be rationally designed and implemented with the participation of health authorities and relevant governmental agencies in order to reduce the incidence and prevalence of CL (16). 
Table 1. The number of CL patients in different province of Iran during 2 years (2011-2013) (16)

\begin{tabular}{|l|l|}
\hline Provinces & The number of CL patients \\
\hline Razavi Khorasan & 13379 \\
\hline Fars & 13356 \\
\hline Isfahan & 8785 \\
\hline Kerman & 4435 \\
\hline Khuzestan & 3615 \\
\hline Ilam & 2027 \\
\hline Golestan & 1960 \\
\hline Northern Khorasan & 1286 \\
\hline Sistan and Balouchestan & 1144 \\
\hline Yazd & 1069 \\
\hline Qom & 1012 \\
\hline Tehran & 848 \\
\hline Semnan & 786 \\
\hline Bushehr & 385 \\
\hline Kermanshah & 355 \\
\hline Hormozgan & 286 \\
\hline Lorestan & 270 \\
\hline Chaharmahal and Bakhtiari & 242 \\
\hline South Khorasan & 226 \\
\hline Hamadan & 209 \\
\hline Kohgiluyeh and Boyer-Ahmad & 195 \\
\hline Mazandaran & 150 \\
\hline Markazi & 115 \\
\hline Alborz & 115 \\
\hline West Azerbaijan & 90 \\
\hline & \\
\hline
\end{tabular}

\section{The Epidemiology of Cutaneous Leishmaniasis in Khorasan-Razavi}

The present study reviews the CL status in different districts of Khorasan-Razavi.

CL has been present for a long time as an important endemic disease in the Khorasan-Razavi province in the North East of Iran (21). The Khorasan-Razavi province has the highest prevalence of CL infection in Iran (16). Since this province has shared borders with Afghanistan and Turkmenistan, changes in the incidence rate and epidemiological pattern of CL might be linked to neighboring countries. In fact, gerbil reservoirs and vectors of ZCL have been confirmed along the border between Iran and Turkmenistan as well as in the Afghan city of Heart which is in an area endemic for ACL and close to Iran $(22,23)$. Most of infected domestic and wild Canidae have been affected by L. infantum in Iran $(24,25)$. However, infections with with $L$. tropica were reported from canidae in Syria, Morocco, and Israel (26-30). Dogs are therefore a secondary reservoir host for L. tropica and for its transmission to human.

Mashhad, the second most populous city in Iran and the capital of Khorasan-Razavi province is located in the North East of Iran and close to the border with Turkmenistan and Afghanistan. Mashhad is one of the main endemic areas for ACL. During the last two decades, CL cases have significantly risen in Mashhad causing concerns in the health authorities (6). According to the KhorasanRazavi Health Center in 2001, the highest prevalence of CL was seen in the region of Ab-o-Bargh, where population density, stray dogs, cultural and economic poverty in suburbs are considered as the main socio-epidemiological risk factors. Haj Norouz is another high disease area in Mashhad due to predisposing factors such as, the existence of building debris, old building with wooden roofs and areas where waste material is accumulated (17).

Neishabur, the former capital of Khorasan-Razavi province, has also been considered as an important endemic city for ACL with the rate of infection in some regions such as Sarcheshmeh and Kariz-no being higher than in others (5). ACL is present in the city of Sabzevar in Khorasan Razavi, while the disease has not been detected in Mazinan in Sabzevar (13).

Sarakhs in the North East of Iran is a high prevalence region for L. major. It is possible that its location on the Silk Road, the proximity to Turkmenistan and the high volume of commercial traffic could underpin the increased incidence of leishmaniasis in this city (31). Torbat-e Jam is another county where many CL cases have been observed annually. This district is located in the South West of Mashhad and north of Taybad, West of the Afghanistan border (32,33).

Based on the clinical appearance of CL lesions, it has been inferred that the patients in the towns of Chenaran and Quchan probably suffer from L. tropica, while L. major has been known as dominant strain of CL in Dargaz and Kalat, that are located in the North and North East, respectively. It is noticeable that Quchan, in the North East of Iran, has a border with Turkmenistan and is connected by road with Chenaran city half way to Mashhad.

Based on the clinical appearance of CL lesions, several investigations have indicated that Torbat-e Heydarieh and Fariman, in the South of Mashhad, are endemic for L. tropica. However, conclusive data on the identification of Leishmania species in this area based on immunological or molecular tools is still lacking. Since these towns are situated on the way of travel to Mashhad, accurate identification of CL agents can be effective to determine the control and prevent strategies (34).

It is still unclear which parasite species cause CL in the cities of Gonabad, Kashmar and Bardaskan in the southwest and Khaf and Taybad districts in the South East of Khorasan-Razavi province.

\section{Identification of the Parasite Species Responsible for Cutaneous Leishmaniasis in Endemic Areas of North East Iran}

The identification of Leishmania species is essential to monitor the spread of the disease as well as to design and implement effective control methods. Since control and prevention of ZCL and ACL are different, several studies have focused on the correct identification of Leishmania species in Khorasan-Razavi during the past two decades (6).

Mohajery et al. (35), used isoenzyme electrophoresis for the identification of Leishmania spp. and showed that Mashhad is the main focus for L. tropica, but L. major was present in other regions, particularly in the suburbs.

In another study, Valizadeh et al. determined the causative species of Leishmania in 72 cases of CL in Mashhad using an ELISA method based on species-specific monoclonal antibodies. 52 cases were identified as L. tropica, 16 as L. major and 4 cases were caused by unidentified species (35). 
Between 2002 and 2005, Hajjaran et al. (4) collected 87 parasite samples from patients with CL who were referred to Mashhad health centers and determined the species of Leishmania by RAPD-PCR. $94.2 \%$ of the isolates were identified as L. tropica, whereas $5.8 \%$ were identified as L. major.

Mahmoudi in 2005 used PCR to determine the causative agent of CL in Mashhad and demonstrated L. major in 2/21 cases and the other samples were identified positive for L. tropica (36). Similar results were reported by Fata et al. (37) in 2007 using the Whatman paper and PCR methods.

The epidemiological pattern of leishmaniasis in Mashhad and the increased incidence of CL in Khorasan-Razavi prompted further studies to identify the main causative agents of CL in other counties of this province.

A study including $84 \mathrm{CL}$ patients in the county of Sabzevar in 2006-2007 detected 32 cases of $L$. tropica and 52 cases of $L$. major. Another study on 52 patients in Neishabur using RAPDPCR only detected L. tropica $(38,39)$. The cities of Sabzevar and Roudab were the foci in the county of Sabzevar where L. tropica was detected, whereas the cities of Hokm Abad, Ghezelgharshi, Joghatay and Mohamad Abad were endemic foci of both L. tropica and L. major (39).

Molecular investigations by Hossein Farash et al. and Saadabadi et al. (40) on 144 patients with CL identified only L. tropica in the districts of Torghabeh-Shandiz (2010) and Kharv (2007), which are close to Mashhad and Neishabur, respectively $(6,40)$. Pagheh et al. reported similar findings in 2013 in Torbat-e Jam in a cohort of 504 patients with Leishmania lesions (32).

In 2013, Shamsian et al. (31) identified L. tropica in 12 patients and L. major in 52 cases in Sarakhs that had previously been known as an area where L. major was prevalent as the cause of ZCL (31).

Despite Khaf and Taybad had been considered as ACL foci ( $L$. tropica) until 2015, Abdolmajid et al. (41) found 20 cases for $L$. major among 66 positive persons with CL by PCR method (41). Using a similar method between 2015 and 2017, Shamsian et al. diagnosed 7 patients with ZCL out of 60 subjects with CL in Torbat-e Heydarieh and 16 with L. major out of 84 patients from Kashmar (11 cases), Bardaskan (2 cases) and Gonabad (3 cases) $(34,42)$.

On the contrary, using PCR in 2015 Fata et al. (36) demonstrated 22 patients infected by $L$. tropica from 85 cases of CL patients in the ZCL foci of Dargaz and Kalat 2015 (29).

13 cases of $L$. tropica out of 42 patients were diagnosed by Shamsian et al. (43) in Fariman, another known focus for L. major, in 2017.

Finally, Shamsian et al. (44) found 29 out of 86 samples positive for L. major in CL infected patients in Quechan and Chenaran despite L. tropica had been considered as the only causative species of $C L$ in this area.

It is noticeable that all the studies reported here, except for the ones in Neishabur, Kharv, and Torbat-e Jam, were performed using the same PCR protocol and same primers that give a 615 bp band for L. major and a $744 \mathrm{bp}$ band for L. tropica (Figure 1,2). These studies are therefore directly comparable (6).

\section{DISCUSSION}

The global epidemiology of $C L$ has changed, mainly due to population movements, individual risk factors and environmental changes. CL is one of emerging parasitic diseases in recent years, posing a public health problem in many parts of the world and is widespread in Iran $(39,40)$. The epidemiology of CL has changed in the past two decades in Iran and both L. tropica and L. major have being present in Khorasan-Razavi province $(17,45)$.

The first step in any control and prevention program for leishmaniasis is the identification of the infectious agents, reservoirs and vectors (35). In recent years, many studies have been conducted in Khorasan-Razavi province with the aim to refine the immunological and molecular diagnosis of the causative Leishmania species (4,6,34,35,39-42,46).

The aim of this review was to design a new epidemiological picture of CL, using data from several studies performed in KhorasanRazavi province to identify the boundary shifts for causative agents of CL during a twenty-year period as the basis to new insights for control and prevention measures.

The investigations carried out in Mashhad demonstrated that ACL and ZCL co-exist. Furthermore, L. tropica has been known the dominant agent causing CL in this city $(4,35,37,46)$. Mashhad is the main focus for ACL, but also is a center for L. major, particularly in suburbs.

Sabzevar, has two foci of CL, one with dry lesions and the other consisting of patients with wet lesions. Until now Sabzevar has been known just as an ACL focus while now both forms (ACL and ZCL) of the disease have been found to exist at this location (39). These epidemiological changes may be due to migration of

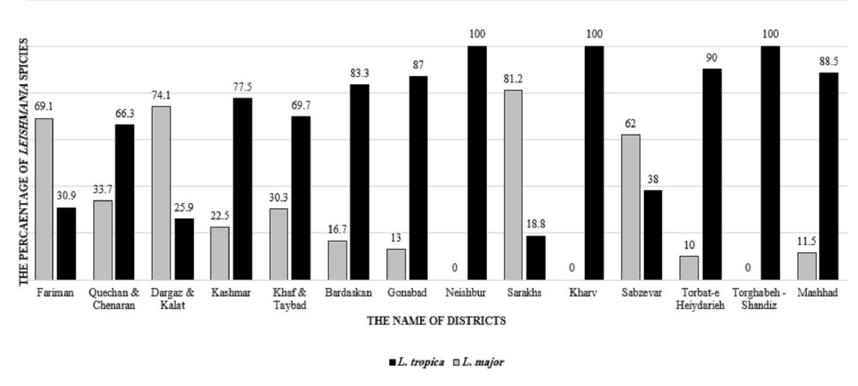

Figure 1. The percentage of Leishmania species frequency in different districts of Khorasan-Razavi

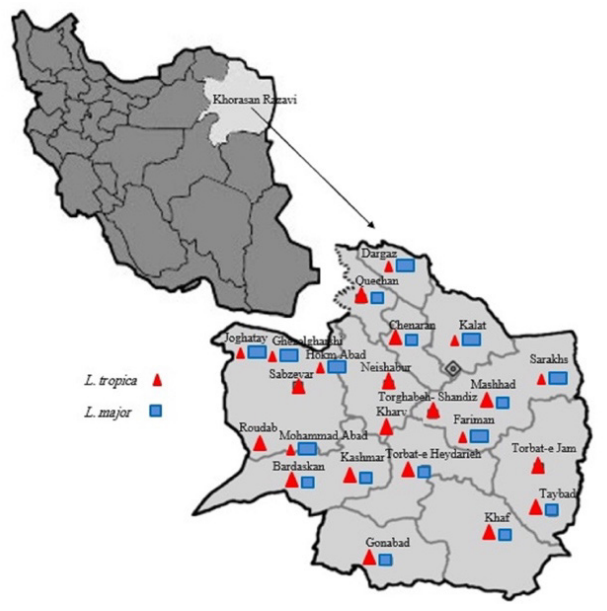

Figure 2. Cutaneous leishmaniasis map of Razavi Khorasan province in 2017 
people from neighboring countries such as Afghanistan and Iraq, rural to urban fluxes which provide suitable conditions for transmission, piling of building debris and litter near residential areas, which lead to expansion of vector reservoirs for both species. Agriculture also causes an increase of $L$. major reservoirs and vector population. Moreover changes in the climate and in people lifestyles or the lack of immunity in people who immigrate to endemic areas are other risk factors that can increase the incidence of CL in a paerticular area $(19,34,35)$. Similar reasons for the epidemiological changes listed above are likely to underpin the variations in the distribution of Leishmania species observed in Torbat-e Heydarieh, Bardaskan, Kashmar, Khaf, Taybad, Quechan and Chenaran $(34,41,42,44)$.

The presence of both L. tropica and L. major species as causes of CL in Sarakhs might be related to its location near an international railroad and in proximity to the border with Turkmenistan; increased movement of people through this region since 2013 is likely to be an additional factor in the observed epidemiological pattern of leishmaniasis (31). The diffusion of L. tropica in Fariman, Kalat, and Dargaz could result from changes in health programs to control the vectors and development of industry and tourisms. Therefore, some of labor migrants or travelers who are infected by $L$. tropica could be reservoir hosts for this emerging agent (36).

Torbat-e Jam, Neishabur, Kharv, Torghabeh-Shandiz are located in the vicinity of Mashhad and similarly to Mashhad have been considered as ACL foci $(6,32,39,40)$. Despite all cases in these regions were identified as $L$. tropica with molecular method, the number of lesions, their morphological characteristics and the season of occurrences in some patients corresponded to the characteristics typical of L. major infections; therefore, it may be desirable to extend and refine the examinations to ensure that cases of ZCL do not go undetected.

\section{CONCLUSION}

CL is a major health problem in Khorasan-Razavi province where most of the regions are affected by both L. tropica and L. major species.

Several measures can be suggested to reduce the incidence of the disease in the urban endemic areas. Classes on health education for inhabitants, reducing the numbers of stray dogs, identification and urgent treatment of clinical cases could be effective. Reduction in rodent and carrier population, removal of waste and environmental modifications should be considered as key health policies in areas with L. major $(6,19)$.

\section{Acknowledgment}

This paper is not financially supported by any organizations. The authors thank from Deputy of Researches of Mashhad University of Medical Sciences and ACECR-Razavi Khorasan branch for their cooperation.

\section{Authorship Contributions}

Concept: B.R.H.F., S.A.S., M.M., A.F., Design: B.R.H.F., S.A.S., M.M., Data Collection or Processing: B.R.H.F., F.S., E.P., Analysis or Interpretation: B.R.H.F., F.S., E.P., Literature Search: B.R.H.F., S.A.S.,Writing: B.R.H.F., F.S., P.M.

Peer-review: Internally peer-reviewed.
Conflict of Interest: The authors declare that they have no conflict of interest.

\section{REFERENCES}

1. Al-Salem WS, Pigott DM, Subramaniam K, Haines LR, Kelly-Hope L, Molyneux DH, et al. Cutaneous Leishmaniasis and Conflict in Syria. Emerg Infect Dis. 2016;22:931-33.

2. Saki J, Tavakoli S, Mardani M, Salmanzadeh S, Karamkhani A. A 5-year period (2010-2014) retrospective study of human cutaneous leishmaniasis in Ahvaz County, southwest of Iran. Asian Pac J Trop Dis 2016;6:429-31.

3. WHO | Leishmaniasis [Internet]. WHO. [cited 2017 Aug 19]. Available from: http://www.who.int/mediacentre/factsheets/fs375/en/

4. Hajjaran H, Mohebali M, Razavi MR, Rezaei S, Kazemi B, Edrissian G, et al. Identification of Leishmania Species Isolated from Human Cutaneous Leishmaniasis, using Random Amplified Polymorphic DNA (RAPD-PCR). Iran J Public Health 2004;33:8-15.

5. Bari AU, Rahman SB. Many faces of cutaneous leishmaniasis. Indian J Dermatol Venereol Leprol 2008;74:23-7.

6. Hosseini Farash BR, Shamsian SA, Rezaee A, Yazdanpanah MJ. Anthroponotic Cutaneous Leishmaniasis in Torghabeh - Shandiz, a Region with Rural Texture (A Molecular Study). Jundishapur J Microbiol 2013;6:e8274.

7. Azizi K, Rassi Y, Javadian E, Motazedian MH, Asgari Q, YaghoobiErshadi MR. First Detection of Leishmania infantum in Phlebotomus (Larroussius) major (Diptera: Psychodidae) from Iran. J Med Entomol 2008;45:726-31.

8. Azizi K, Rassi Y, Moemenbellah-Fard MD. PCR-based detection of Leishmania major kDNA within naturally infected Phlebotomus papatasi in southern Iran. Trans R Soc Trop Med Hyg 2010;104:440-2.

9. Rassi Y, Javadian E, Nadim A, Rafizadeh S, Zahraii A, Azizi K, et al. Phlebotomus perfiliewi transcaucasicus, a vector of Leishmania infantum in northwestern Iran. J Med Entomol 2009;46:1094-8.

10. Bailey F, Mondragon-Shem K, Hotez P, Ruiz-Postigo JA, Al-Salem W, Acosta-Serrano Á, et al. A new perspective on cutaneous leishmaniasisImplications for global prevalence and burden of disease estimates. PLoS Negl Trop Dis 2017;11:e0005739.

11. Mathers CD, Ezzati M, Lopez AD. Measuring the Burden of Neglected Tropical Diseases: The Global Burden of Disease Framework. PLoS Negl Trop Dis 2007;1e114.

12. Alvar J, Vélez ID, Bern C, Herrero M, Desjeux P, Cano J, et al. Leishmaniasis Worldwide and Global Estimates of Its Incidence. PLOS ONE 2012;7:e35671.

13. GBD 2015 Disease and Injury Incidence and Prevalence Collaborators. Global, regional, and national incidence, prevalence, and years lived with disability for 310 diseases and injuries, 1990-2015: a systematic analysis for the Global Burden of Disease Study 2015. Lancet Lond Engl 2016;388:1545-602.

14. Behravan M, Moin-Vaziri V, Haghighi A, Rahbarian N, Taghipour N, Abadi A, et al. Molecular Identification of Leishmania Species in a Re-Emerged Focus of Cutaneous Leishmaniasis in Varamin District, Iran. J ArthropodBorne Dis 2017;11:124-31.

15. Yaghoobi-Ershadi M. Phlebotomine Sand Flies (Diptera: Psychodidae) in Iran and their Role on Leishmania Transmission. J Arthropod-Borne Dis 2012;6:1-17.

16. Norouzinezhad F, Ghaffari F, Norouzinejad A, Kaveh F, Gouya MM. Cutaneous leishmaniasis in Iran: Results from an epidemiological study in urban and rural provinces. Asian Pac J Trop Biomed 2016;6:614-9.

17. Nadim A, Javadian E, Noushin MK, Nayil AK. Epidemiology of cutaneous leishmaniasis in Afghanistan. Part I: Zoonotic cutaneous leishmaniasis. Bull Soc Pathol Exot Filiales 1979;72:31-5.

18. Razmjou S, Hejazy H, Motazedian MH, Baghaei M, Emamy M, Kalantary M. A new focus of zoonotic cutaneous leishmaniasis in Shiraz, Iran. Trans R Soc Trop Med Hyg 2009;103:727-30. 
19. Holakouie-Naieni K, Mostafavi E, Boloorani AD, Mohebali M, Pakzad R. Reprint of "Spatial modeling of Cutaneous Leishmaniasis in Iran from 1983 to 2013." Acta Trop 2017;165:90-5.

20. Salah AB, Kamarianakis Y, Chlif S, Alaya NB, Prastacos P. Zoonotic cutaneous leishmaniasis in central Tunisia: spatio temporal dynamics. Int J Epidemiol 2007;36:991-1000.

21. Khazaei S, Hafshejani AM, Saatchi M, Salehiniya H, Nematollahi S. Epidemiological Aspects of Cutaneous Leishmaniasis in Iran. Arch Clin Infect Dis 2015;10:e28511.

22. Bakhshi H, Oshaghi MA, Abai MR, Rassi Y, Akhavan AA, Sheikh Z, et al. Molecular detection of Leishmania infection in sand flies in border line of Iran-Turkmenistan: restricted and permissive vectors. Exp Parasitol. 2013;135:382-387.

23. Fakhar M, Karamian M, Ghatee MA, Taylor WR, Pazoki Ghohe H, Rasooli SA. Distribution pattern of anthroponotic cutaneous leishmaniasis caused by Leishmania tropica in Western Afghanistan during 2013-2014. Acta Trop. 2017;176:22-28.

24. Alawieh A, Musharrafieh U, Jaber A, Berry A, Ghosn N, Bizri AR. Revisiting leishmaniasis in the time of war: the Syrian conflict and the Lebanese outbreak. Int J Infect Dis 2014;29:115-119.

25. Moghaddas E, Fata A, Zarean M, Derakhshani M, Fakhar M, Shamsian SA. Investigation of Visceral Leishmaniasis among 192 Dog Carcasses Killed by Road Accidents in Khorasan Razavi, North-eastern Iran during 2014-2016. Iran J Public Health [Internet]. 2018;47:1742-1748.

26. Mohebali M, Hajjaran H, Hamzavi Y, Mobedi I, Arshi S, Zarei Z, et al. Epidemiological aspects of canine visceral leishmaniosis in the Islamic Republic of Iran. Vet Parasitol. 2005;129:243-251.

27. Mohebali M, Malmasi A, Hajjaran H, Jamshidi S, Akhoundi B, Rezaei $\mathrm{M}$, et al. Disseminated Leishmaniasis Caused by Leishmania tropica in a Puppy from Karaj, Central Iran. Iran J Parasitol. 2011;6:69-73.

28. Dereure J, Rioux JA, Khiami A, Pratlong F, Périères J, Martini A. [Ecoepidemiology of leishmaniases in Syria. 2--Presence, in dogs, of Leishmania infantum Nicolle and Leishmania tropica (Wright) (Kinetoplastida-Trypanonomatidae)]. Ann Parasitol Hum Comp. 1991;66:252-255.

29. Dereure J, Rioux JA, Gallego M, Perières J, Pratlong F, Mahjour J, et al. Leishmania tropica in Morocco: infection in dogs. Trans R Soc Trop Med Hyg. 1991;85:595.

30. Baneth G, Yasur-Landau D, Gilad M, Nachum-Biala Y. Canine leishmaniosis caused by Leishmania major and Leishmania tropica: comparative findings and serology. Parasit Vectors. 2017;10:113.

31. Ali S, Shamsian S, Rezaee SA., Amin A, Razieh B, Hosseini Farash R. Molecular Identification of Leishmania tropica in an Endemic Border City for Zoonotic Cutaneous Leishmaniasis (ZCL) in Northeastern Iran. 2015;2.

32. Pagheh AS, Fakhar M, Sharif M, Danesh V, Ahmadi Z. Epidemiological Survey of Cutaneous Leishmaniasis due to Leishmania tropica in a New Focus in Khorasan Razavi Province. J Mazandaran Univ Med Sci [Internet]. 2013;23:46-52.

33. Torbat-e Jam. In: Wikipedia [Internet]. 2017. Naseri A, Fata A, Rezai A, Hedayatimoghadam M, Berengi F, Akbarzadeh O, et al. Molecular identification of Leishmania species in Torbat-e Heydarieh, Khorasan Razavi province, Iran. Int J Med Res Health Sci [Internet]. 2016;5:87-92.

34. Naseri A, Fata A, Rezai A, Hedayatimoghadam M, Berengi F, Akbarzadeh $\mathrm{O}$, et al. Molecular identification of Leishmania species in Torbat-e Heydarieh, Khorasan Razavi province, Iran. Int J Med Res Health Sci [Internet]. 2016;5:87-92.

35. Valizadeh M, Fata A, A K, Mohajery M, Dalimi Asl H. A Study On Leishmania Species Causing Cutaneous Leishmaniasis Inmashhad Using Specific Monoclonal Antibodies. 2005;;7:107-113.

36. Fata A, Rezaee SAR, Shamsian SA, Vafa M, Sadat F, Moghaddas E. Identification of Cutaneous Leishmaniasis Species in the Dargaz City, Iran. Esfahan MedJ [Internet]. 2017;34.

37. Fata A, Khamesipour A, Mohajery M, Hosseininejad Z, Afzalaghaei M, Berenji F, et al. Whatman Paper (FTA Cards) for Storing and Transferring Leishmania DNA for PCR Examination. Iran J Parasitol [Internet]. 2009;4:37-42.

38. Mohajery M, Hajjaran H, Shamsian SA, Sadabadi F, Afshari J. Identification of different species of Leishmania parasite causing cutaneous leishmaniasis by RAPD-PCR in Neishabour in 1385-1386. Iran J public health. 2000;4-1:177-190.

39. Mohajery M, Shamsian SA, Rezaee A, Kazem HP, Taghi SM, Gholamreza F, et al. Evaluation Of Mulecular Epidemiology Of Cutaneous Leishmaniasis In Sabzevar. 2017;53:138-144

40. Saadabadi F, Mohajery M, Poostchi E, Shamsian SAA. Identification of Leishmania species causing cutaneous leishmaniasis using Random Amplified Polymorphic DNA (RAPD-PCR) in Kharve, Iran. Rep Biochem Mol Biol [Internet]. 2013;1:69.

41. Abdolmajid F, Ghodratollah SS, Hushang R, Mojtaba MB, Ali MM, Abdolghayoum M. Identification of Leishmania species by kinetoplast DNA-polymerase chain reaction for the first time in Khaf district, Khorasan-e-Razavi province, Iran. Trop Parasitol. 2015;5:50-54.

42. Rezaee AR, Shamsian SA, Naseri A, Bagherpoor MR, Moghaddas E. Identification of Leishmania Species for Cutaneous leishmaniasis in Gonabad, Bardaskan and Kashmar, Central Khorasan, 2015. JUNDISHAPUR J Microbiol [Internet]. 2017;10.

43. Fata A, Moghaddas E, Rezee A, Abdali A, Jarahi L, Shamsian A. Epidemiological Study of Cutaneous Leishmaniasis and Identification of Etiological Species. J Mazandaran Univ Med Sci [Internet]. 2018;27:12331.

44. Moghaddas E, Fata A, Gholampour A, Jarahi L, Soleimanpour S, Shamsian SA. Species Identification of Cutaneous Leishmaniasis in Quchan, Northeast of Iran. J Kermanshah Univ Med Sci [Internet]. 2019 ;In Press(In Press).

45. Aflatoonian MR, Sharifi I, Aflatoonian B, Shirzadi MR, Gouya MM, Kermanizadeh A. A Review of Impact of Bam Earthquake on Cutaneous Leishmaniasis and Status: Epidemic of Old Foci, Emergence of New Foci and Changes in Features of the Disease. J Arthropod-Borne Dis [Internet]. 2016;10:271-280.

46. Mahmoodi M, Masoud M, Afshari J, Shakeri M, Panah M, Berenji F, et al. Molecular identification of Leishmania species causing cutaneous leishmaniasis in Mashhad, Iran. Jundishapur J Microbiol. 2010;3. 